\title{
Botrytis polyphyllae: A New Botrytis Species Causing Gray Mold on Paris polyphylla
}

\author{
Shan Zhong, ${ }^{1}$ Jing Zhang, ${ }^{2}$ and Guo-Zhen Zhang ${ }^{1, \dagger}$ \\ ${ }^{1}$ Ministry of Agriculture Key Laboratory of Pest Monitoring and Green Management, Department of Plant Pathology, College of \\ Plant Protection, China Agricultural University, Beijing 100193, China \\ ${ }^{2}$ State Key Laboratory of Agricultural Microbiology and Key Laboratory of Plant Pathology of Hubei Province, Huazhong \\ Agricultural University, Wuhan 430070, China
}

\begin{abstract}
Paris polyphylla is an important perennial medicinal plant in China. A disease similar to gray mold on $P$. polyphylla occurred at the seedling stage in March 2016 and 2017 in Tengchong city, Yunnan Province of China. The disease resulted in up to $50 \%$ mortality in serious cases. Isolates from diseased plants grew $10.6 \mathrm{~mm} /$ day at $20^{\circ} \mathrm{C}$ on PDA. After 21 days, sclerotia were spherical to elliptical $(0.4-2.5 \times 0.3-1.8 \mathrm{~mm})$.

$526-1,064 \times 12-15 \mu \mathrm{m}$. Isolates did not form conidiophores or conidia on PDA or MYA. A phylogenetic analysis based on G3PDH, RPB2, and HSP60 sequence data supported assignment of three representative isolates as a new species of Botrytis. Based on morphological, phylogenetic characteristics and Koch's Postulates, the causal agent of gray mold on $P$. polyphylla was identified as a novel species, Botrytis polyphyllae.
\end{abstract} Conidia from diseased tissues were hyaline to pale brown, long, ovoid, unicellular, and measured 15.1-24.5 × 8.8-13.4 $\mu \mathrm{m}$; conidiophores were
Keywords: Paris polyphylla, gray mold
Paris polyphylla (family Trilliaceae) is an important perennial medicinal plant, and its dried rhizome is used in traditional Chinese medicine for its anti-inflammatory and hemostatic effects (Zhao et al. 2014). The demand for the rhizome is increasing by $20 \%$ every year, and approximately 3,000 tons were consumed in China in 2012 (Yang et al. 2012). The cultivation area of $P$. polyphylla is becoming larger as wild P. polyphylla is very limited. During March of 2016 and 2017 in Tengchong City, Yunnan Province of China, seedlings of $P$. polyphylla developed symptoms of gray mold. Infected leaves and petioles were water-soaked and rotted. Stem infections resulted in damping-off. Up to $50 \%$ of the plants were affected. During periods of high humidity, lesions became covered with gray mold; morphology of conidia and conidiophores were consistent with those of Botrytis.

The genus Botrytis is the focus of intensive scientific research worldwide. It can infect more than 1,400 species of cultivated plants, many of which are important agricultural crops, such as strawberries and table grapes (Fillinger and Elad 2015). The genus Botrytis has been divided into 22 species based on Hennebert's taxonomy (Hennebert 1973). In the last decade, at least 10 new species have been identified based on their morphological and molecular characteristics (Ferrada et al. 2016; Garfinkel et al. 2017; Grant-Downton et al. 2014; Li et al. 2012; Saito et al. 2016; Walker et al. 2011; Zhang et al. 2010a, b, 2016; Zhou et al. 2014).

To date, the identification of Botrytis spp. has mainly relied on morphological characteristics such as colony morphology, conidial shape and size, and the organization and size of the sclerotia (Hennebert 1973). However, morphological features are usually

${ }^{\dagger}$ Correspondence author: G.-Z. Zhang; zhanggzh@cau.edu.cn

Funding: This work was supported by the Special Fund for Agro-Scientific Research in the Public Interest of China (No. 201303025).

*The $\boldsymbol{e}$-Xtra logo stands for "electronic extra" and indicates that one supple-
mentary table is published online.

The author(s) declare no conflict of interest.

Accepted for publication 20 February 2019.

@ 2019 The American Phytopathological Society inconsistent among different Botrytis species or isolates. Currently, DNA-based molecular techniques have been developed and are widely used for fungal identification. These include DNA sequencing of internal transcribed spacer regions (ITS) (White et al. 1990) and other protein coding sequences. Phylogenetic analyses using a single gene or a multilocus analysis generated from loci such as glyceraldehyde-3-phosphate dehydrogenase (G3PDH), heat shock protein 60 (HSP60), and the second-largest subunit of DNAdependent RNA polymerase II (RPB2) genes have been used to support morphological characteristics (Staats et al. 2005).

The pathogen of gray mold on Rhizoma paridis (Paris polyphylla) leaves was reported to be $B$. cinerea in Hubei Province, China (You et al. 2014). In the present study, symptoms of diseased plants found in Yunnan Province, China shared similarities with gray mold. However, the cultural characteristics of the isolates were different from those of $B$. cinerea. The aim of this study was to identify the causal agent and describe the species of Botrytis obtained from $P$. polyphylla based on morphological characteristics and multigene molecular phylogeny, and to assess pathogenicity to several fruits and dicotyledonous plants.

\section{Materials and Methods}

Fungal isolation. Samples of diseased $P$. polyphylla were collected in Yunnan Province, China in March 2016 and 2017. To obtain cultures, diseased tissue pieces were soaked in $10 \mathrm{ml}$ of a $3 \%$ $\mathrm{NaOCl}$ solution for $1 \mathrm{~min}$, washed with sterile distilled water (SDW) three times, and subsequently plated on potato dextrose agar (PDA) (200 g of potato, $20 \mathrm{~g}$ of glucose, and $20 \mathrm{~g}$ of agar per liter). Cultures were incubated at $20^{\circ} \mathrm{C}$ in the dark for $48 \mathrm{~h}$ and then transferred to new plates of PDA. Isolates were purified by transferring hyphal tips to PDA, incubation at $20^{\circ} \mathrm{C}$, and stored in PDA tubes at $4^{\circ} \mathrm{C}$.

Morphological and biological characteristics. Three isolates (YN1, YN2, and YN3) were selected for morphological and biological characterization. To observe colony morphology, mycelial plugs were transferred from the edge of 5-day-old colonies onto fresh PDA plates and incubated at $20^{\circ} \mathrm{C}$ in the dark. Thirty sclerotia were randomly chosen from each isolate for measurement after 21 days. To enhance sporulation, mycelial plugs were inoculated onto both PDA and malt yeast extract agar (MYA) (10 g of malt extract, $4 \mathrm{~g}$ of glucose, $4 \mathrm{~g}$ of yeast extract, and $15 \mathrm{~g}$ of agar per liter) and placed under near-UV light. 


\begin{tabular}{|c|c|c|c|c|c|c|}
\hline \multirow[b]{2}{*}{ Species } & \multirow[b]{2}{*}{ Isolate } & \multirow[b]{2}{*}{ Host } & \multirow[b]{2}{*}{ Location } & \multicolumn{3}{|c|}{ GenBank accession no. } \\
\hline & & & & RPB2 & HSP60 & G3PDH \\
\hline B. polyphyllae & YN1 & Paris polyphylla & Tengchong & MG431975 & MG431978 & MG387957 \\
\hline B. polyphyllae & YN2 & P. polyphylla & Tengchong & MG431976 & MG431979 & MG387958 \\
\hline B. polyphyllae & YN3 & P. polyphylla & Tengchong & MG431977 & MG431980 & MG387959 \\
\hline
\end{tabular}

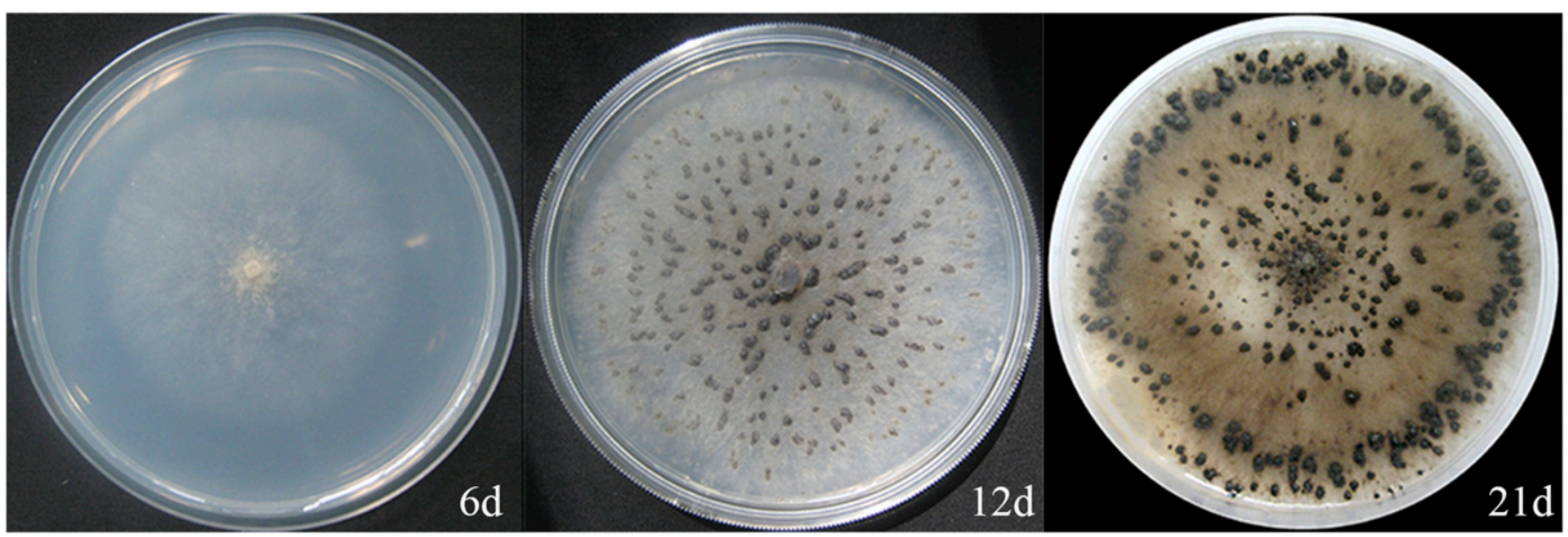

Fig. 1. Colonial morphology of YN3 on PDA at $20^{\circ} \mathrm{C}$ after incubation for 6 days, 12 days, and 21 days. The mycelium was pale gray to brown; the abundant sclerotia were light brown to black; no conidia and conidiophores produced.

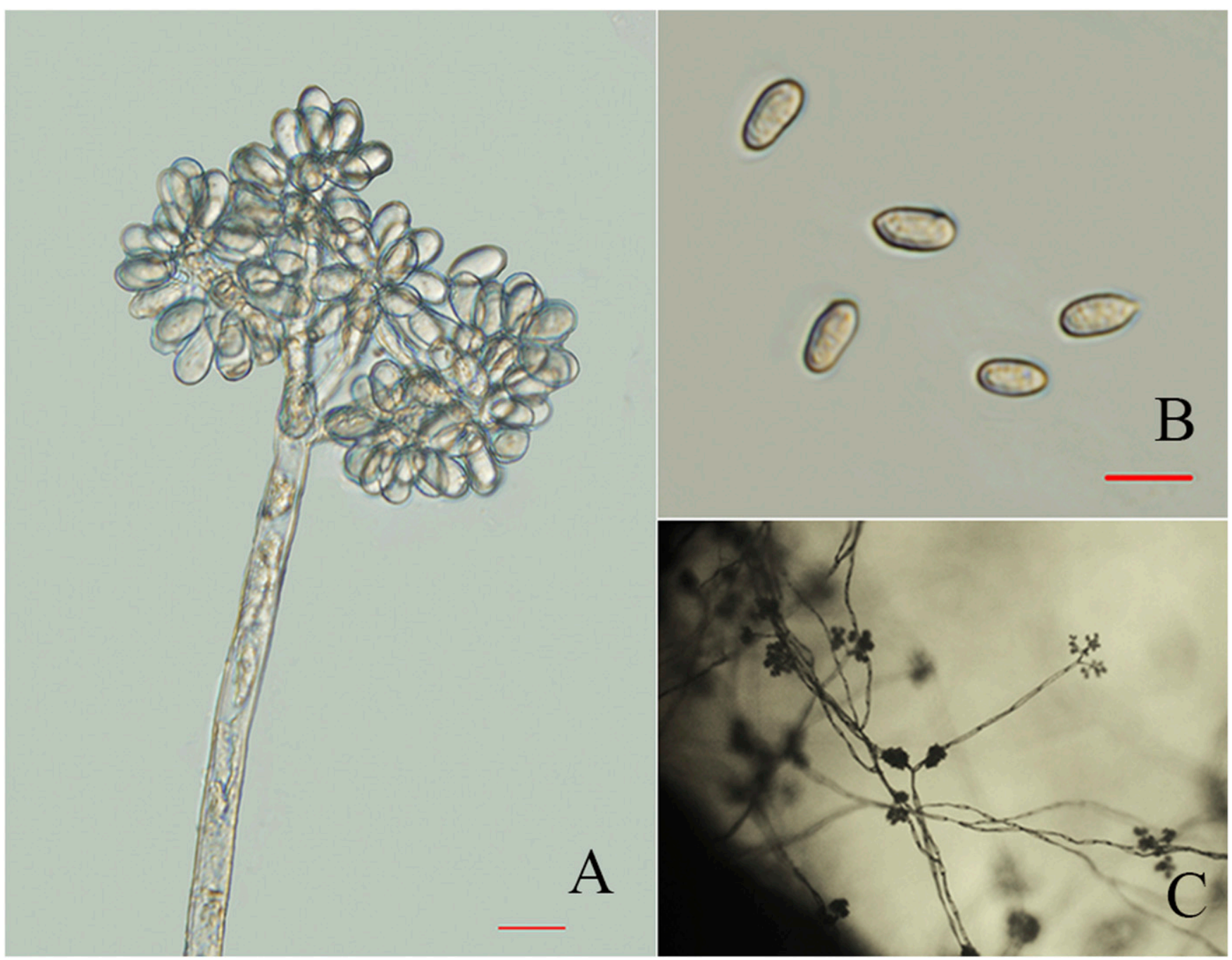

Fig. 2. Morphological characters of conidiophores and conidia of YN3 from the diseased plant. A and C, Conidiophores were straight, septate, pale brown, branching alternate or whorled near the top. B, The conidia were hyaline to pale brown, long ovoid, unicellular. Bars $=20 \mu \mathrm{m}$. 
To determine the optimum temperature for colony growth of the isolates, mycelial plugs ( $5 \mathrm{~mm}$ diameter) were plated on new fresh PDA plates (90 mm diameter) and incubated at 5, 10, 15, 20, 25, 30 , and $35^{\circ} \mathrm{C}$. Each of the three isolates was tested at all 7 temperatures with 5 replicates per isolate. Colony diameter was measured after 5 days of incubation. The colony growth rate was calculated by diameter and expressed as millimeters per day.

DNA extraction, PCR amplification, and sequencing. Genomic DNA was extracted from 3 isolates by the CTAB method according to Gawel and Jarret (1991) with a slight modification. Four loci including ITS, G3PDH, RPB2, and HSP60 were amplified with the primer pairs ITS1/ITS4 (White et al. 1990), G3PDHfor/ G3PDHrev, RPB2for/RPB2rev, and HSP60for/HSP60rev (Staats et al. 2005), respectively. PCR amplification protocols were performed as previously described (Staats et al. 2005; White et al. 1990). The amplified products of each gene were separated by agarose gel $(1 \%, \mathrm{wt} / \mathrm{vol})$ electrophoresis and sequenced by TSINGKE, Beijing, China with a 3730 DNA Analyzer (Applied Biosystems, U.S.A.). Sequences obtained from forward and reverse primers were analyzed with the BioEdit sequence alignment editor 7.1.11 to obtain consensus sequences (Hall 1999) and were submitted to GenBank (Table 1).

Phylogenetic analysis. Partial gene sequences of G3PDH, RPB2, and HSP60 were used to establish a concatenated dataset $(G 3 P D H+$ RPB2 + HSP60) and three individual datasets (G3PDH, RPB2, and HSP60). The phylogenetic analysis included the 3 isolates collected in this study and reference isolates representing 35 species of Botrytis (Garfinkel et al. 2017; Grant-Downton et al. 2014; Li et al. 2012; O'Gorman et al. 2008; Rupp et al. 2017; Saito et al. 2014, 2016; Staats et al. 2005; Zhang et al. 2010a, b, 2016; Zhou et al. 2014). Strain 9201 of Monilinia fructigena and strain 484 of Sclerotinia sclerotiorum (Staats et al. 2005) were used as outgroups (Supplementary Table S1). Botrytis mali was deleted from the combined dataset and the separate HSP60 and RPB2 datasets, because the HSP60 and RPB2 gene sequences were absent. Maximum likelihood (ML) trees were computed in MEGA 6.0 (Tamura et al. 2013). The pairwise alignment parameters were gap opening penalty 15 and gap extension penalty 6.66 . The multiple alignment parameters were gap opening penalty 15 , gap extension penalty 6.66 , the delay divergent cutoff $30 \%$; DNA weight matrix IUB, transition weight 0.5 , negative matrix off, and delay divergent cutoff $30 \%$. All positions containing gaps were excluded from the analysis. The bootstrap consensus tree was inferred from 1,000 replicates. Branches corresponding to partitions reproduced in $<50 \%$ bootstrap replicates were collapsed. The alignments and trees were deposited in TreeBASE (S23565, S23566, S23567, S23568).

Pathogenicity tests. Isolate YN3 was used to inoculate detached leaves and stems of $P$. polyphylla seedlings. Five stem segments injured with a sterilized insect needle $1 \mathrm{~mm}$ deep and 10 uninjured leaves were placed on a plastic tray. Mycelial plugs ( $3 \mathrm{~mm}$ diameter) cut from the edge of a 5-day-old colony were transferred onto the stem segments and leaves individually. Five stem segments injured as above and 10 uninjured leaves were treated with PDA plugs ( $3 \mathrm{~mm}$ diameter) alone and used as controls. High relative humidity was maintained by covering the tray with plastic wrap. The tray was incubated at $20^{\circ} \mathrm{C}$ in the dark for $24 \mathrm{~h}$ and then in $12 \mathrm{~h}$ light/ $12 \mathrm{~h}$ dark for 7 days.

Pathogenicity to fruits of strawberry (Fragaria $\times$ ananassa), cherry tomato (Solanum lycopersicum), cherry (Cerasus pseudocerasus), table grape (Vitis vinifera), and cucumber (Cucumis sativus) was determined with isolate YN3. Ten fruits of each plant (cherry tomato, cherry, table grapes, and cucumber) injured with a 3mm-diameter puncher and 10 uninjured fruits (strawberry) were inoculated with 5-day-old mycelial plugs ( $3 \mathrm{~mm}$ diameter). Ten fruits of the four plants injured as above and 10 uninjured strawberry fruits were inoculated with PDA plugs ( $3 \mathrm{~mm}$ diameter) to serve as controls. The incubation conditions were the same as above.

Disease incidence $(\%)$ was calculated as the percentage of host tissues (leaves, stem segments, or fruits) with lesions among the total number of the leaves (stems segments or fruits) inoculated with the isolate.

\section{Results}

Taxonomic description. Botrytis polyphyllae Shan Zhong \& Guo-Zhen Zhang, sp. nov. (Figs. 1-2)

MycoBank: MB823456

Holotype: China, Yunnan Province, Tengchong City, $25^{\circ} 03^{\prime} \mathrm{N}$, $98^{\circ} 50^{\prime} \mathrm{E}$, dried culture of YN3 isolated from a diseased leaf of Paris polyphylla, 29 Mar 2017, G. Z. Zhang, holotype HMAS 247741, ex-type culture CGMCC 3.18842.

Etymology: polyphyllae, refers to the host species, polyphylla.

Descriptions: Colonies grew on PDA at an average rate of $10.6 \mathrm{~mm} /$ day at $20^{\circ} \mathrm{C}$. Colonies were pale gray to brown with abundant sclerotia (Fig. 1), but no conidia or conidiophores were formed

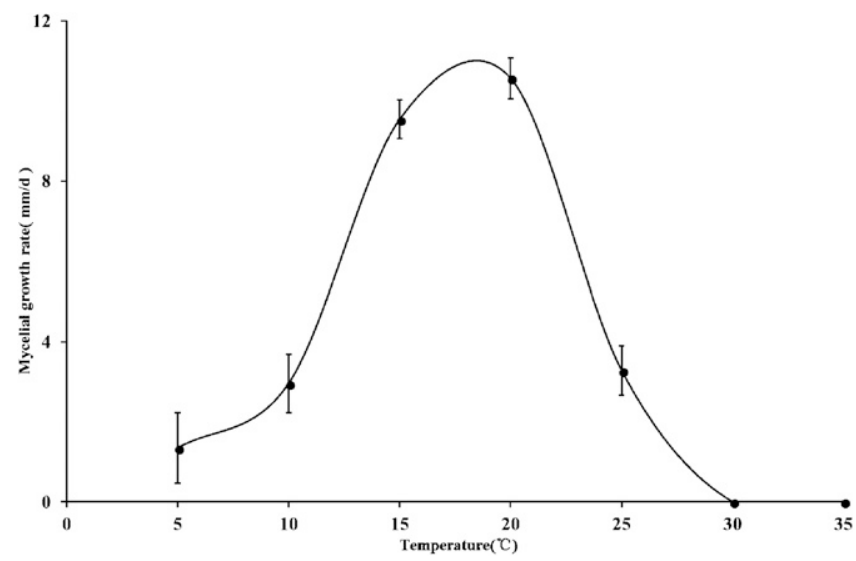

Fig. 3. Average colony growth rate of three isolates on PDA at 5 to $35^{\circ} \mathrm{C}$. The bar represents the standard errors of the means $(n=15)$.

Table 2. Colony growth rate and morphological characteristics of selected Botrytis spp.

\begin{tabular}{|c|c|c|c|c|c|}
\hline \multirow[b]{2}{*}{ Species } & \multirow[b]{2}{*}{ Isolate } & \multirow[b]{2}{*}{ Growth $^{\mathbf{a}}(\mathrm{mm} /$ day $)$} & \multicolumn{2}{|c|}{ Sclerotia } & \multirow[b]{2}{*}{ Reference } \\
\hline & & & Shape $^{b}$ & Size (mm) & \\
\hline B. polyphyllae & YN3 & 10.6 & $\mathrm{I}, \mathrm{OE}, \mathrm{S}$ & $0.4-4.5 \times 0.3-2.2$ & This study \\
\hline B. sinoviticola & GBC-5 & 13 & $\mathrm{I}, \mathrm{OE}, \mathrm{S}$ & $1.0-2.2 \times 1.0-2.0$ & Zhou et al. 2014 \\
\hline B. californica & X503 & 13.5 & $\mathrm{I}, \mathrm{OE}, \mathrm{S}$ & $0.6-4.2 \times 0.6-2.3$ & Saito et al. 2016 \\
\hline B. calthae & N.D. ${ }^{c}$ & N.D. & I, OE, S & $3.4-5.5 \times 0.2-3.4$ & Hennebert and Groves 1963 \\
\hline B. pseudocinerea & N.D. & N.D. & $\mathrm{I}, \mathrm{OE}, \mathrm{S}$ & $2.2-5.5 \times 1.1-3.4$ & Walker et al. 2011 \\
\hline B. fabae & BC-22 & 13 & I, OE, S & $0.4-3.2 \times 0.3-2.1$ & Zhang et al. 2010a \\
\hline B. pelargonii & N.D. & N.D. & HS & $2.5-4.8 \times 1.9-2.4$ & Mirzaei et al. 2008 \\
\hline B. cinerea & BC-1 & 17 & I, OE, S & $0.7-27.5 \times 0.5-12$ & Zhang et al. 2010a \\
\hline
\end{tabular}

${ }^{\mathrm{a}}$ Growth $=$ Colony growth rate $\left(\mathrm{PDA}, 20^{\circ} \mathrm{C}\right)$.

${ }^{b}$ Shape of sclerotia: $\mathrm{HS}=$ hemispherical, $\mathrm{I}=$ irregular, $\mathrm{OE}=$ oblong/elliptical, $\mathrm{S}=$ spherical.

${ }^{\mathrm{c}}$ N.D. $=$ not determined 
on PDA and MYA even under near-UV light; sclerotia were solitary to aggregated, dark brown to black, irregular, spherical to elliptical, $0.4-2.5 \times 0.3-1.8 \mathrm{~mm}$ (av. $1.5 \times 1.0 \mathrm{~mm}, n=30$ ) (Fig. 1). Conidiophores from diseased plants were straight, septate, pale brown, branching alternate or whorled near the top, 526-1,064 $\times$ $12-15 \mu \mathrm{m}$ (Fig. 2A); conidia from diseased plants were hyaline to pale brown, long ovoid, unicellular, 15.1-24.5 × 8.8-13.4 $\mu \mathrm{m}$ (av. $21.1 \times 11.3 \mu \mathrm{m}, n=50)$ (Fig. 2B) (Table 2).

The optimum temperature for colony growth on PDA was $20^{\circ} \mathrm{C}$; no growth occurred above $30^{\circ} \mathrm{C}$ (Fig. 3). This relatively low temperature may reflect an adaption to the cool environment of Yunnan Province.

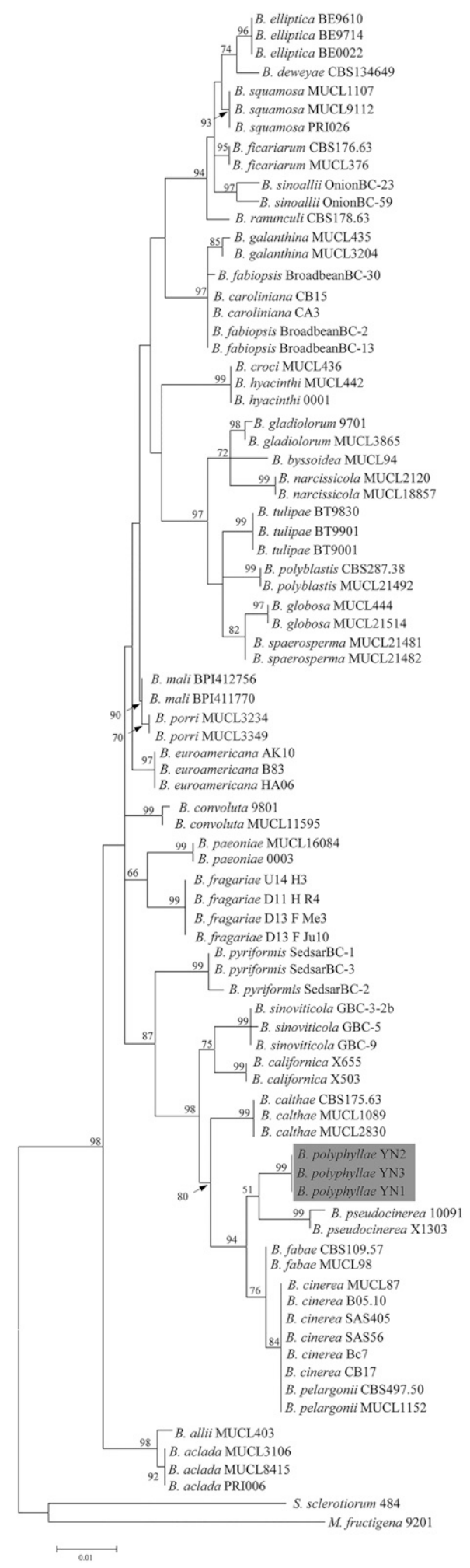

Fig. 4. Molecular phylogeny of Botrytis species and outgroups Monilinia fructigena and Sclerotinia sclerotiorum presented in a maximum-likelihood tree inferred from the dataset containing partial DNA sequences of G3PDH. The numbers at each node indicate the bootstrap percentage $(n=1,000)$. Bootstrap support values less than $50 \%$ are not shown. Isolates of YN1, YN2, and YN3 were collected in this study.

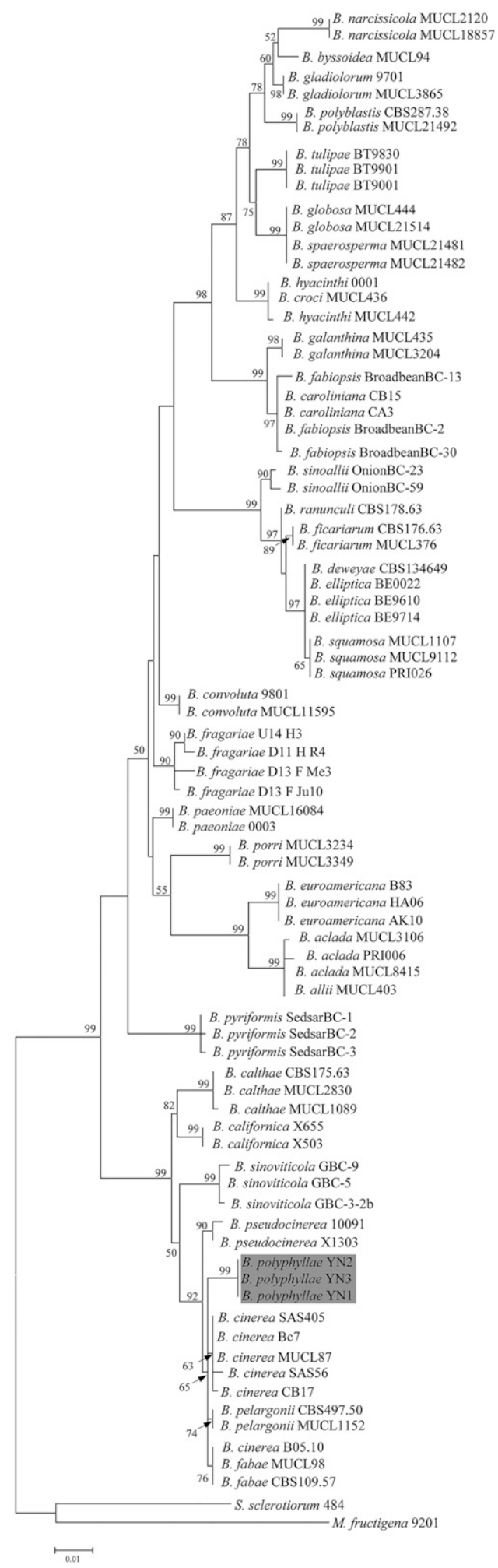

Fig. 5. Molecular phylogeny of Botrytis species and outgroups Monilinia fructigena and Sclerotinia sclerotiorum presented in a maximum-likelihood tree inferred from the dataset containing partial DNA sequences of RPB2. The numbers at each node indicate the bootstrap percentage $(n=1,000)$. Bootstrap support values less than $50 \%$ are not shown. Isolates of YN1, YN2, and YN3 were collected in this study. 
Phylogenetic analysis. Only two nucleotide differences in 418 base pairs of the partial ITS sequences of $B$. cinerea (AM235297), B. pseudocinerea (JN692379), B. pelargonii (AJ716290), B. fabae (AJ716303), and Botrytis sp. were seen in this study. The ITS sequences do not have sufficient resolution for the phylogenetic analysis (Saito et al. 2016; Zhang et al. 2016).
The sequences of the three representative isolates in this study (Table 1), as well as those from other Botrytis species and outgroups (M. fructigena and S. sclerotiorum) obtained from GenBank were used for a phylogenetic analysis. The DNA sequences of G3PDH, RPB2, and HSP60 were used to establish three separate datasets and a combined dataset. Individual alignment datasets for each

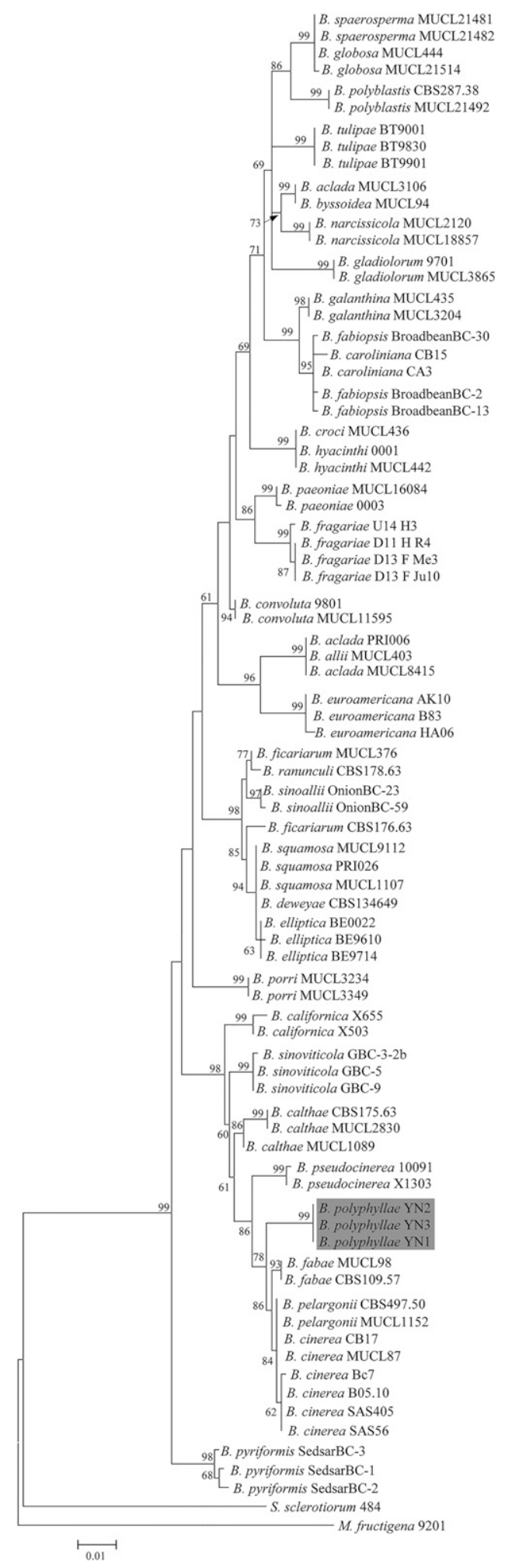

Fig. 6. Molecular phylogeny of Botrytis species and outgroups Monilinia fructigena and Sclerotinia sclerotiorum presented in a maximum-likelihood tree inferred from the dataset containing partial DNA sequences of HSP60. The numbers at each node indicate the bootstrap percentage $(n=1,000)$. Bootstrap support values less than $50 \%$ are not shown. Isolates of YN1, YN2, and YN3 were collected in this study.

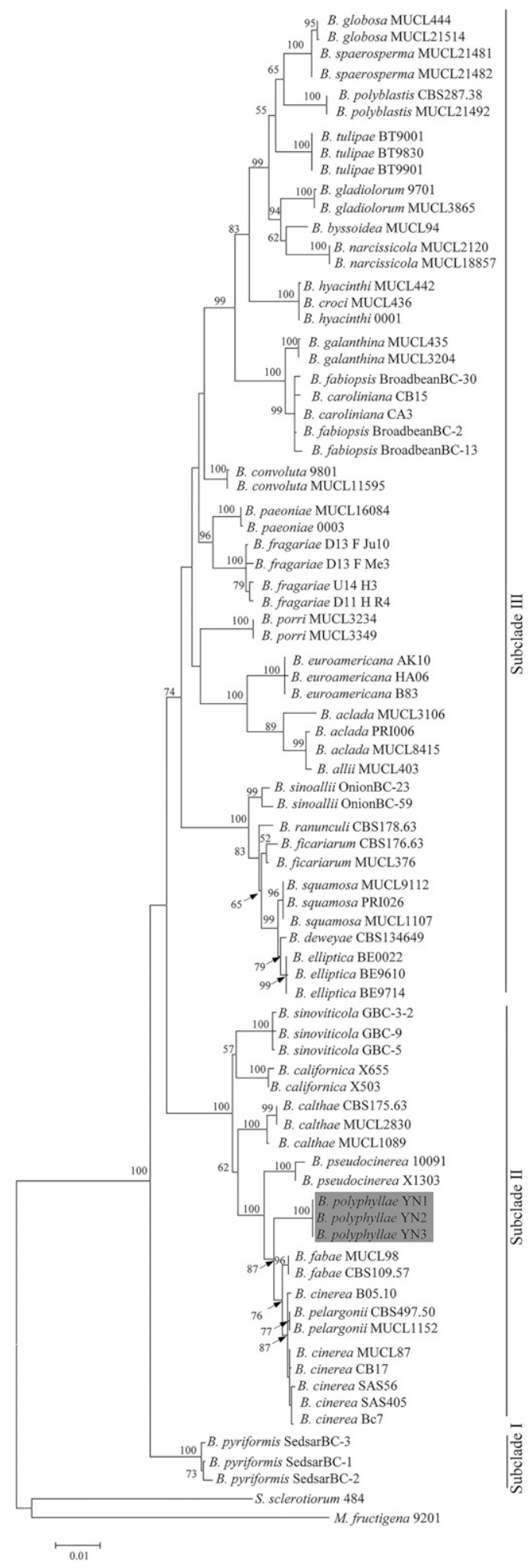

Fig. 7. Molecular phylogeny of Botrytis species and outgroups Monilinia fructigena and Sclerotinia sclerotiorum presented in a maximum-likelihood tree inferred from the dataset containing partial DNA sequences of G3PDH, RPB2, and HSP60. The numbers at each node indicate the bootstrap percentage $(n=1,000)$. Bootstrap support values less than $50 \%$ are not shown. Isolates of YN1, YN2, and YN3 were collected in this study. 
marker consisted of 83 sequences for G3PDH, 81 for RPB2, and 81 for HSP60. The combined dataset consisted of 81 fungal taxa. Individual gene analyses and the combined gene analysis (G3PDH + RPB2 + HSP60) resulted in similar tree topologies (Figs. 4-7).

The results of the concatenated dataset showed that members of the genus Botrytis formed three subclades (I, II, and III) (Fig. 7). Eight Botrytis species, B. californica, B. calthae, B. cinerea, B. fabae, B. pelargonii, B. pseudocinerea, B. sinoviticola, and Botrytis sp. in this study formed subclade II with $100 \%$ bootstrap support. Our Botrytis sp. was recognized as a separate taxon in the phylogenetic tree, and was most closely related to $B$. cinerea, B. pelargonii, and B. fabae.

Pathogenicity. Leaves of $P$. polyphylla inoculated with the new Botrytis species developed light brown spots with a water-soaked halo 3 days after inoculation (Fig. 8C). After 7 days, lesions were water-soaked and rotted with $80 \%$ incidence (Fig. 8D). Stem segments developed fusiform lesions 7 days after inoculation with $100 \%$ incidence (Fig. 8E). No symptoms were observed on the noninoculated control leaves and stems. Koch's Postulates were fulfilled by reisolating the same pathogen from the diseased tissues.

The fruits of strawberry, cherry tomato, and cherry inoculated with mycelial plugs showed rot 4 days postinoculation (Fig. $8 \mathrm{~F}-\mathrm{H}$ ), and no symptoms were observed on the table grapes and cucumber and noninoculated control fruits (not shown).

\section{Discussion}

This study describes a new species of Botrytis, B. polyphyllae, on the basis of multilocus phylogenetic analyses and morphological characteristics that facilitate their distinction from other Botrytis species. Our results, which were based on the phylogenetic analyses of
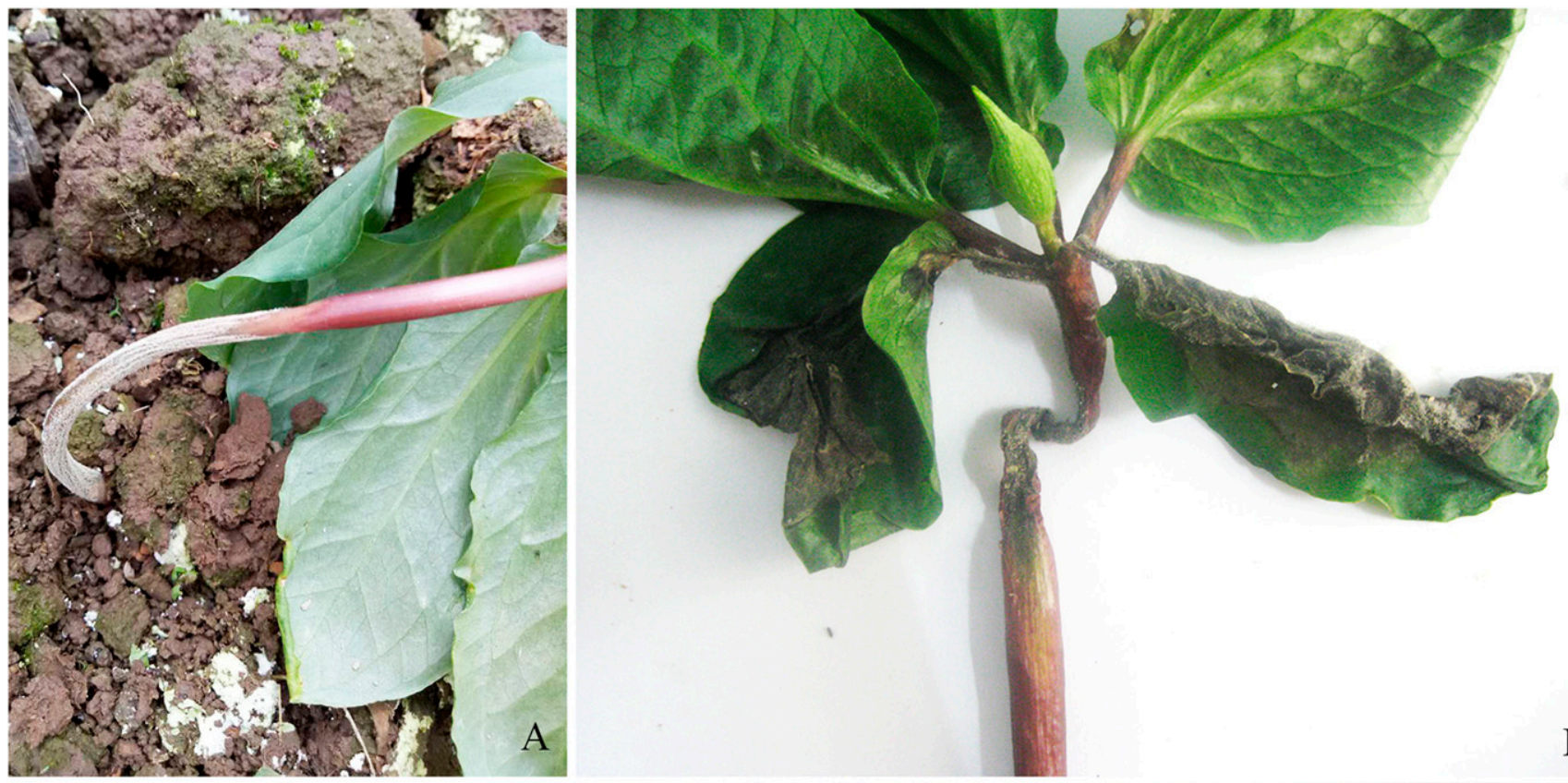

B
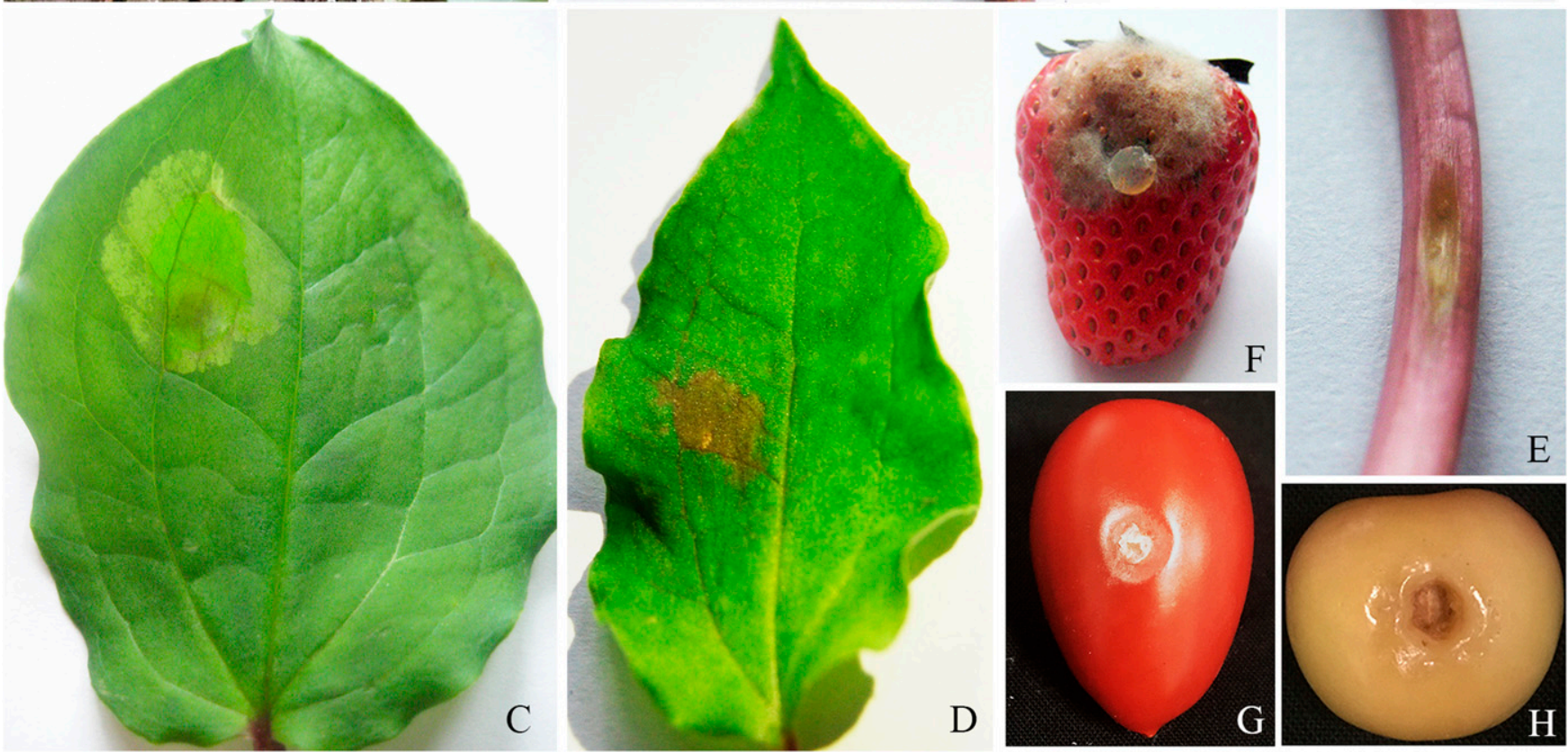

Fig. 8. Symptoms of Botrytis polyphyllae on various hosts. A and B, Paris polyphylla infection in the field: diseased plants showed damping-off, white to gray mold appeared at the base of the stem; the leaves were water soaked, and dark brown to black rot was present on the petiole base. $\mathrm{C}$ to $\mathrm{E}$, Pathogenicity of isolate YN3 to detached noninjured leaves and injured stem segments from P. polyphylla: the leaves showed light brown spots and the tissues became hyaline around the spots after 3 days and the spots turned brown to black after 7 days; stems showed fusiform lesions after 7 days. $\mathrm{F}$ to $\mathrm{H}$, Pathogenicity of isolate YN3 to strawberry, cherry tomato and cherry fruits: strawberry developed a gray rot, cherry tomato and cherry fruit rotted after 4 days. 
four datasets, indicated that Botrytis species fall into three subclades (Fig. 7). The newly described taxon, B. polyphyllae, was a separate species clustered with high bootstrap support and was more closely related to B. cinerea, B. pseudocinerea, B. pelargonii, and B. fabae in subclade 2.

B. polyphyllae formed conidia and conidiophores on P. polyphylla but did not sporulate on PDA or MYA in this study. This phenotype was also found in another Botrytis species, B. caroliniana, which was in the subclade III based on the molecular data and isolated from blackberry ( $\mathrm{Li}$ et al. 2012). The morphological characteristics supported the segregation of $B$. polyphyllae from its closest phylogenetic sister taxa. The sclerotia of $B$. polyphyllae were $0.4-2.5 \times$ $0.3-1.8 \mathrm{~mm}$, and they were smaller than those of most other Botrytis species (Table 2).

Botrytis species are divided into two subclades in the phylogenetic tree by the partial genes (G3PDH, RPB2, and HSP60) (Staats et al. 2005). The subclade containing $B$. cinerea infects dicotyledons in general, while the subclade containing $B$. aclada infects monocotyledons. In this study, $B$. polyphyllae clustered to the same subclade with $B$. cinerea. $B$. polyphyllae infects $P$. polyphylla in nature, and by artificial inoculation, the fruit of strawberry, cherry tomato, and cherry, but not table grapes or cucumber. An extensive investigation should be carried out to determine the host range of B. polyphyllae. $B$. cinerea has been reported to cause gray mold on the foliage of $R$. paridis ( $P$. polyphylla) in Hubei Province, China (You et al. 2014). To our knowledge, this is the first report of gray mold caused by the newly described B. polyphyllae on P. polyphylla in Yunnan Province, China.

\section{Literature Cited}

Ferrada, E. E., Latorre, B. A., Zoffoli, J. P., and Castillo, A. 2016. Identification and characterization of Botrytis blossom blight of Japanese plums caused by Botrytis cinerea and B. prunorum sp. nov. in Chile. Phytopathology 106: 155-165.

Fillinger, S., and Elad, Y. 2015. Botrytis-the fungus, the pathogen and its management in agricultural systems. Springer International Publishing AG, Switzerland.

Garfinkel, A. R., Lorenzini, M., Zapparoli, G., and Chastagner, G. A. 2017. Botrytis euroamericana, a new species from peony and grape in North America and Europe. Mycologia 109:495-507.

Gawel, N. J., and Jarret, R. L. 1991. A modified CTAB DNA extraction procedure for Musa and Ipomoea. Plant Mol. Biol. Rep. 9:262-266.

Grant-Downton, R. T., Terhem, R. B., Kapralov, M. V., Mehdi, S., RodriguezEnriquez, M. J., Gurr, S. J., van Kan, J. A. L., and Dewey, F. M. 2014. A novel Botrytis species is associated with a newly emergent foliar disease in cultivated Hemerocallis. PLoS One 9:e89272.

Hall, T. A. 1999. BioEdit: a user-friendly biological sequence alignment editor and analysis program for Windows 95/98/NT. Nucleic Acids Symp. Ser. 41:95-98.

Hennebert, G. L. 1973. Botrytis and Botrytis-like genera. Persoonia 7:183-204.

Hennebert, G. L., and Groves, J. W. 1963. Three new species of Botryotinia on Ranunculaceae. Can. J. Bot. 41:341-370.
Li, X. P., Kerrigan, J., Chai, W. X., and Schnabel, G. 2012. Botrytis caroliniana, new species isolated from blackberry in South Carolina. Mycologia 104: 650-658.

Mirzaei, S., Goltapeh, E. M., Shams-Bakhsh, M., and Safaie, N. 2008. Identification of Botrytis spp. on plants grown in Iran. J. Phytopathol. 156: 21-28.

O'Gorman, D. T., Sholberg, P. L., Stokes, S. C., and Ginns, J. 2008. DNA sequence analysis of herbarium specimens facilitates the revival of Botrytis mali, a postharvest pathogen of apple. Mycologia 100:227-235.

Rupp, S., Plesken, C., Rumsey, S., Dowling, M., Schnabel, G., Weber, R. W. S., and Hahn, M. 2017. Botrytis fragariae, a new species causing gray mold on strawberries, shows high frequencies of specific and efflux-based fungicide resistance. Appl. Environ. Microbiol. 83:e00269-e17.

Saito, S., Margosan, D., Michailides, T. J., and Xiao, C. L. 2016. Botrytis californica, a new cryptic species in the $B$. cinerea species complex causing gray mold in blueberries and table grapes in California. Mycologia 108: 330-343.

Saito, S., Michailides, T. J., and Xiao, C. L. 2014. First report of Botrytis pseudocinerea causing gray mold on blueberry in North America. Plant Dis. $98: 1743$.

Staats, M., van Baarlen, P., and Van Kan, J. A. L. 2005. Molecular phylogeny of the plant pathogenic genus Botrytis and the evolution of host specificity. Mol. Biol. Evol. 22:333-346.

Tamura, K., Stecher, G., Peterson, D., Filipski, A., and Kumar, S. 2013. MEGA 6: molecular evolutionary genetics analysis 6.0. Mol. Biol. Evol. 30:2725-2729.

Walker, A. S., Gautier, A., Confais, J., Martinho, D., Viaud, M., Pêcheur, P. L., Dupont, J., and Fournier, E. 2011. Botrytis pseudocinerea, a new cryptic species causing gray mold in French vineyards in sympatry with Botrytis cinerea. Phytopathology 101:1433-1445.

White, T. J., Bruns, T., Lee, S., and Taylor, J. W. 1990. Amplification and direct sequencing of fungal ribosomal RNA genes for phylogenetics. Pages 315-322 in: PCR protocols, a guide to methods and applications. M. A. Innis, D. H. Gelfand, J. J. Sninsky, and T. J. White, eds. Academic, San Diego.

Yang, L. Y., Yang, B., Wang, X., Li, L. Y., Dong, Z. Y., Yan, S. W., and Li, S. P. 2012. The advances on breeding of Paris polyphylla Smith var. yunnanensis (Franch.) Hand.-Mazz. J. Agric. 2:22-24.

You, J. M., Wang, Q. H., Lin, X. M., Guo, J., Ai, L. Q., Zhang, M. D., Mu, S., Guo, X. L., He, Y. S., Liu, H. H., Wang, H., Zhang, Y., and Zhao, R. J. 2014. First report of gray mold of Rhizoma paridis caused by Botrytis cinerea in China. Plant Dis. 98:1434.

Zhang, J., Wu, M. D., Li, G. Q., Yang, L., Yu, L., Jiang, D. H., Huang, H. C., and Zhuang, W. Y. 2010a. Botrytis fabiopsis, a new species causing chocolate spot of broad bean in central China. Mycologia 102:1114-1126.

Zhang, J., Yang, H., Yu, Q., Wu, M., Yang, L., Zhuang, W. Y., Chen, W. D., and Li, G. Q. 2016. Botrytis priformis sp. nov. a novel and likely saprophytic species of Botrytis. Mycologia 108:682-696.

Zhang, J., Zhang, L., Li, G. Q., Yang, L., Jiang, D. H., Zhuang, W. Y., and Huang, H. C. 2010b. Botrytis sinoallii, a new species of the gray mold pathogen on Allium crops in China. Mycoscience 51:421-431.

Zhao, D. X., Li, C., Zhao, G. X., and Li, Y. 2014. Research progress on genuine medicinal plant Paris polyphylla var. yunnanensis (Trilliaceae) in Yunnan. Chin. J. Trop. Agric. 34:42-47.

Zhou, Y. J., Zhang, J., Wang, X. D., Yang, L., Jiang, D. H., Li, G. Q., Hsiang, T., and Zhuang, W. Y. 2014. Morphological and phylogenetic identification of Botrytis sinoviticola, a novel cryptic species causing gray mold disease of table grapes (Vitis vinifera) in China. Mycologia 106:43-56. 